\title{
Políticas públicas, juventude e desigualdades sociais: uma discussão sobre o ProJovem Urbano em Belo Horizonte
}

Geraldo Leão

Symaira Poliana Nonato

Universidade Federal de Minas Gerais

\section{Resumo}

0 artigo discute alguns resultados de uma pesquisa qualitativa realizada entre 2009 e 2011 que investigou as trajetórias de jovens participantes do Programa ProJovem Urbano (Programa Nacional de Inclusão de Jovens) no ano de 2009, em Belo Horizonte, Minas Gerais. Procurou-se compreender a vivência da condição juvenil pelos participantes do programa a partir de suas experiências de escolarização e trabalho e de seus projetos de futuro, para assim compreender os significados e sentidos do programa para eles. $\mathrm{Na}$ primeira etapa da pesquisa, foram aplicados 103 questionários a fim de construir um breve perfil socioeconômico dos alunos. Após o levantamento inicial dos dados, duas turmas foram selecionadas e observadas. Posteriormente, foram selecionados dez jovens para a realização de entrevistas semiestruturadas. A pesquisa revelou uma maioria de mulheres, negros e jovens em condições precárias de trabalho ou desempregados e com uma sociabilidade restrita em relação a outros estratos da população. Evidenciou-se que as desigualdades sociais têm uma importância central nas trajetórias de vida desses jovens, com impactos marcantes em suas experiências atuais e em suas expectativas em relação ao futuro. Com base nesse solo comum, foi possível perceber uma diversidade de experiências a partir das quais são produzidos diferentes significados e motivações em relação à escolarização, o que delimitava também a relação construída com o programa. De uma maneira geral, a busca pela certificação escolar era o principal interesse dos participantes.

\section{Palavras-chave}

Jovens - Educação - Políticas públicas.

\section{Contato:}

Geraldo Leão

Universidade Federal de Minas Gerais

Faculdade de Educação

Belo Horizonte/MG

glea02001@yahoo.com.br 


\section{Public policies, youth and social inequalities: a discussion about ProJovem Urbano in the city of Belo Horizonte (Brazil)}

Geraldo Leão

Symaira Poliana Nonato

Universidade Federal de Minas Gerais

\section{Abstract}

This paper discusses some of the outcomes of a qualitative research carried out between 2009 and 2011 which investigated the trajectories of young participants in the Program ProJovem Urbano (National Program for Youth Inclusion) in 2009, in the city of Belo Horizonte, state of Minas Gerais, in Brazil. The attempt was to understand the experience of juvenile status by the program participants based on their schooling and previous jobs as well as their projects for the future, with the purpose of comprehending the meanings and impacts of the program for them. In the first phase of the research 103 questionnaires were applied with the aim of depicting a brief socioeconomic profile of students. After the initial data survey, two classes were selected and observed. Later on, 10 students were selected to undergo a semi-structured interview. The research revealed that most participants were female, Black, young people in precarious conditions of work or unemployed and with a limited sociability in relation to other sectors of the population. It was evident that social inequalities play a central role in the trajectories of these youngster's lives, with outstanding impacts in their current experiences and in the expectations regarding their future. Based on this common ground, it was possible to realize that there is a variety of experiences which are the starting point from where different meanings and motivations are produced in relation to school education, which also defined the relationship they established with the program. Generally speaking, the search for a school certificate was the main interest of participants.

\section{Keywords}

Youth - Education - Public policies.

Contact:

Geraldo Leão

Universidade Federal de Minas Gerais

Faculdade de Educação

Belo Horizonte/MG

gleao2001@yahoo.com.br 
Este texto é fruto de uma pesquisa ${ }^{1}$ que teve como objetivo investigar as trajetórias de vida de jovens participantes do Programa ProJovem Urbano - Programa Nacional de Inclusão de Jovens: Educação, Qualificação e Ação, no município de Belo Horizonte. Tratase de um programa do Governo Federal desenvolvido em parceria com Estados e municípios e voltado para jovens de 18 a 29 anos sem o ensino fundamental completo.

0 ProJovem foi implantado em 2005 como um componente estratégico da Política Nacional da Juventude do Governo Lula. Com o slogan Conhecimento e oportunidade para todos, ele tem como objetivo central a certificação no ensino fundamental por meio de uma formação integrada em três eixos: escolarização, qualificação profissional e ação comunitária. 0 programa prevê ainda o pagamento de uma bolsa mensal de cem reais para alunos que tiverem 75\% de frequência.

Em 2007, com a Medida Provisória $\mathrm{n}^{\circ}$ 411/07, o programa passou a abrigar outras ações específıcas voltadas a jovens e adolescentes já desenvolvidas no âmbito do Governo Federal, com o objetivo de promover a integração dessas ações entre si. Sob o nome de ProJovem Urbano, a faixa etária atendida foi ampliada de 24 para 29 anos, prolongou-se o período de funcionamento de doze para dezoito meses e passou-se a admitir jovens com vínculo empregatício. Segundo algumas análises, essas reformulações tiveram impactos positivos quanto ao atendimento, embora permaneçam ainda muitos desafios em relação às condições de funcionamento dos cursos e à garantia da continuidade dos estudos dos jovens (ANDRADE; ESTEVES; OLIVEIRA, 2009).

Em Belo Horizonte, previa-se atender a 3.200 jovens, divididos em dezesseis núcleos. Foram matriculados 4.118 jovens para o programa na turma de 2009, e, desse total, 3.469

1- Pesquisa Educação, condição juvenil e políticas públicas: trajetórias de vida de estudantes do ProJovem Urbano em Belo Horizonte (2009-2011), financiada pela Fundação de Apoio à Pesquisa de Minas Gerais (FAPEMIG). Agradecemos à Coordenação Municipal do ProJovem Urbano de Belo Horizonte 0 apoio concedido para a realização da pesquisa. tiveram sua matrícula confirmada. Porém, apenas 2.198 jovens iniciaram o curso, sendo que somente $1.079(49,1 \%)$ concluíram-no. Desse montante, 873 receberam a certificação de conclusão do ensino fundamental, o que corresponde a 39,7\% das matrículas iniciais (BELO HORIZONTE, 2011).

Para a realização desta pesquisa, foram visitadas três escolas onde funcionavam seis turmas. Foram aplicados 103 questionários a fim de construir um breve perfil dos alunos. Após o levantamento inicial dos dados sobre o perfil dos jovens, duas turmas foram selecionadas e observadas durante os meses de junho a novembro de 2009 com o intuito de compreender a dinâmica das atividades e o cotidiano dos alunos no programa. Posteriormente, foram selecionados dez jovens - seis homens e quatro mulheres - para entrevistas semiestruturadas a partir de critérios como faixa etária, sexo, situação de trabalho e nível de envolvimento com o programa. Esperava-se, assim, contemplar a diversidade percebida no perfil dos jovens que frequentavam o programa, sem se prender à representatividade desses atributos pessoais verificada na pesquisa quantitativa. Com o objetivo de garantir a viabilidade da pesquisa, optou-se por uma conduta metodológica mais flexível quanto a esse aspecto, tendo em vista a inconstância percebida na frequência dos alunos.

Inicialmente, o artigo discute alguns dados gerais sobre o perfil socioeconômico dos alunos com base no questionário aplicado pela pesquisa. Em seguida, a partir das entrevistas concedidas, alguns aspectos acerca das trajetórias de escolarização e trabalho desses jovens são analisados. Por fım, o artigo destaca a experiência juvenil e os projetos de futuro dos jovens, no intuito de indicar questões importantes a serem consideradas sobre os processos educativos em que esses jovens estão inseridos.

\section{Um breve perfil dos jovens}

Um olhar sobre os dados do perfil dos estudantes indica algumas marcas da condição 
juvenil nas camadas populares comuns à experiência de vida da maior parte dos entrevistados. Assim como em outros estudos sobre o perfil dos matriculados no programa, a pesquisa encontrou mais mulheres nas turmas (59\%), fato que se comprovou nas observações in loco realizadas nas escolas. Quanto à cor, 52\% declararam-se pardos e $41 \%$ pretos, o que perfaz um conjunto de 93\% de alunos pertencentes à raça negra.

Outros 36\% declararam ter filhos. Dentre eles, 67\% eram solteiros, 31\% casados e 2\% divorciados ou separados. Quanto à moradia, $43 \%$ dos jovens declararam morar com os pais, $25 \%$ com o/a companheiro/a e 17\% sozinhos. 0 trabalho fazia-se presente no cotidiano desses alunos: 66\% trabalhavam na época da pesquisa, ao passo que 33\% não estavam ocupados.

Quanto à escolarização, 39\% dos entrevistados chegaram a cursar a $5^{\mathrm{a}}$ ou a $6^{\mathrm{a}}$ série, e $43 \%$, a $7^{\text {a }}$ ou a $8^{\text {a }}$ série do ensino fundamental. Cerca de um terço deles (34\%) estudou pela última vez há menos de quatro anos. Assim, tratava-se de jovens com uma escolarização recente e com uma longa permanência nos sistemas de ensino, acumulando muitas reprovações e desistências, fato que irá expressar-se nas trajetórias relatadas.

Traçando um perfil geral desses jovens, podemos dizer que se tratava de um público originário das camadas populares, em sua maioria negros, solteiros, que moravam com os pais. Quase metade deles tinha filhos. Boa parte desses jovens teve uma experiência escolar marcada por reprovações e abandonos, o que gerou várias interrupções em seus percursos. Quanto ao trabalho, em geral, ocupavam postos de trabalhos precários e informais, muitos em tempo parcial, mal remunerado e com baixa qualificação.

\section{As marcas da juventude empobrecida: origem familiar, escolarização e trabalho}

Ao narrarem suas histórias de vida, os depoimentos dos jovens entrevistados apresentavam as marcas das desigualdades sociais vividas desde a infância. Havia dois casos de jovens que moraram na rua junto com a família. Outro estudante, Ricardo ${ }^{2}$, ex-presidiário, trazia a marca da violência que muitas vezes atinge os jovens pobres. Quatro jovens eram migrantes de cidades do interior de Minas Gerais e chegaram a Belo Horizonte em busca de uma melhor alternativa de trabalho.

A maior parte dos entrevistados relatou que os pais eram analfabetos ou semialfabetizados. Em apenas dois casos havia mães com o ensino fundamental incompleto. Os pais exerciam ocupações sem qualificação, sendo trabalhadores(as) rurais, domésticas, garis, salgadeiras etc.

Em geral, os irmãos pararam de estudar antes da conclusão da educação básica e não estudavam mais. Outros estavam matriculados em cursos de educação de jovens e adultos (EJA). Porém, havia alguns casos de famílias cujos filhos concluíram ou cursavam o ensino médio ou superior, o que reflete a expansão recente desse nível de ensino no Brasil, que atingiu as gerações mais novas.

Um olhar para essas trajetórias juvenis revela grande complexidade. Eles apresentavam, em seus percursos educacionais e ocupacionais, as marcas de uma infância empobrecida. Ainda não haviam completado o ensino fundamental e a maioria ocupava postos de trabalho precários e com baixa qualificação ou estavam desempregados. Por outro lado, alguns alcançaram ou tinham possibilidades de almejar uma condição social melhor que a de seus pais, tendo acesso a bens (casa própria, celulares, motos), serviços e a uma maior escolaridade, elementos antes vetados aos seus grupos familiares. Os jovens apresentavam, assim, a experiência da inclusão subalterna que marca o modelo de modernização econômica e social vivida na sociedade brasileira (MARTINS, 1997). Nesse contexto contraditório, eles não se mantinham passivos como vítimas da exclusão social, mas elaboravam sonhos e estratégias para a realização de seus projetos, o que quase sempre incluía a escola e o trabalho.

\section{2- Para resguardar os entrevistados, serão utilizados nomes fictícios.}


Escolarização: experiência da exclusão

As trajetórias escolares dos entrevistados foram marcadas por constantes idas e vindas, devido aos mais diversos motivos. 0 baixo capital cultural e escolar dos pais teve um peso importante nos percursos acidentados dos filhos no ensino fundamental.

Também impactaram negativamente na trajetória escolar dos jovens as várias mudanças de escola. Muitas vezes, os entrevistados tiveram dificuldades para recordar as escolas que frequentaram durante a vida. 0 pai de Cátia era trabalhador rural em propriedades próximas a Sete Lagoas e vivia uma mobilidade muito grande em relação ao local de trabalho, o que fez com que ela e os irmãos experimentassem muitas mudanças de escola. Para outros, as trocas de escola foram provocadas pela separação dos pais, como nos casos de Bruno e Ricardo. Este último residiu sozinho dos 11 aos 13 anos, quando os pais se separaram, o que foi muito negativo para sua vida escolar naquele momento: "Tipo assim, eu ia uma vez ou outra na escola. Eu não morava com meu pai, não tinha ninguém para me controlar."

Em outros casos, a interrupção da trajetória escolar esteve associada à migração para Belo Horizonte. Era o caso de dois ex-trabalhadores rurais (Marcos e Leonardo) ou das jovens que se mudaram para Belo Horizonte a fim de trabalhar no serviço doméstico para famílias da capital (Cátia e Debora).

Assim, não se pode dizer que um único fator tenha determinado o fracasso na trajetória de escolarização desses jovens. Pelo contrário, parece haver uma configuração de fatores que confluem para a decisão de interromper os estudos. Da mesma forma, eles elaboram diversos sentidos e sentimentos em relação aos seus percursos escolares, revelando diferentes modos de subjetivação em relação à escola, modos estes que orientam suas lógicas de ação em relação ao presente, quando foram retomados os estudos no programa (DUBET, 2003).
Dos alunos entrevistados, alguns apresentaram mais dificuldades com relação ao desempenho escolar, o que contribuiu para reforçar um sentimento de inferioridade em relação aos estudos. Carla parece ser a que mais se aproximava desse perfil. Ela tinha 30 anos, era solteira e trabalhava como faxineira desde os 15 anos de idade. Sempre teve muita dificuldade na escola. Estudou em duas instituições até a $5^{\text {a }}$ série, sempre vivendo sucessivas repetências. Estudou pela última vez aos 24 anos, quando abandonou definitivamente a escola para retornar ao ProJovem aos 28 anos. Ela chegava sempre mais cedo para as aulas e raramente faltava. Era muito alegre e acolhedora com os colegas e procurava desenvolver as atividades com envolvimento, mas tinha alguns problemas em acompanhar as aulas. Muitas vezes, aparentava certa ingenuidade em suas participações na sala e em interações com os colegas.

Outros jovens remetiam a um processo de subjetivação do tipo contra a escola. Segundo François Dubet (2003), para salvarem sua dignidade, alguns jovens decidem não participar do jogo escolar, assumindo posturas de indisciplina, evasão e/ou agressividade. Eram os casos de Ricardo, Bruno, Cintia e Jonathan. Todos eles atribuíram ao fato de não gostarem de estudar o motivo pelo abandono escolar. Durante a infância, as atitudes de indisciplina e as fugas da escola foram associadas aos colegas, o que se acentuou a partir da adolescência, quando a socialização se dá fortemente mediada pelo círculo de amizades.

0 caso mais explícito dessa postura refere-se à trajetória de Jonathan. Com 19 anos, ele era o caçula de uma família de cinco irmãos. Jonathan era solteiro, natural de Belo Horizonte. Morava com a mãe, a irmã e um irmão. Todos os seus irmãos completaram o ensino médio e a irmã era professora de informática. Segundo relatou, ele tinha bom desempenho, mas não gostava de estudar. Sua trajetória foi marcada por muitas transferências escolares, devido a motivos variados, sendo que, em um dos casos, foi expulso 
por indisciplina. Ele se dizia um aluno normal quando estava fora da sala de aula. Sua grande dificuldade estaria em se identificar como aluno, em entrar no jogo escolar: "Tipo que eu só me matriculava e só meu nome que estava na escola". Jonathan conta que parou de estudar na $6^{a}$ série, depois de um episódio em que detonou uma bomba fabricada por ele na gaveta da mesa da diretora. Ele responsabilizava somente a si próprio por deixar de estudar: "Tive oportunidade e parei”.

Um dos grandes desafios para as instituições escolares e seus professores com relação aos jovens pobres diz respeito à necessidade de motivá-los para a vida escolar (VAN ZANTEN, 2008). Alguns estudos indicam que a falta de motivação é um dos principais fatores que influenciam no abandono escolar no Brasil (NERI, s/d). Essa parece ser uma experiência comum na vida da maioria dos adolescentes e jovens brasileiros, muitas vezes manifestando-se de forma ambígua. Ao mesmo tempo, há uma grande pressão social em torno da importância da educação, que, reproduzida pelos pais e amigos, tende a ser reconhecida pelos jovens como um valor.

Nos depoimentos coletados, os entrevistados tendiam a ver os estudos como uma necessidade, muito mais do que como algo que lhes dava prazer. Poderíamos falar aqui de uma relação instrumental com o estudo, em especial com o saber, na qual o saber não tem relação consigo mesmo, mas serve para fins externos, tal como afirma Bernard Charlot (2000). Nesse sentido, a aquisição do conhecimento escolar tende a ter um custo pessoal maior, sendo muitas vezes fonte de sofrimento. A educação assumia para eles o tom de uma imposição social que exigia sacrifícios e força de vontade (correr atrás), uma exigência do mercado de trabalho ou uma condição para melhorar de vida. Estando eles marcados por experiências negativas em relação à escola e, ao mesmo tempo, sendo obrigados a reconhecer sua importância, ao menos como instituição credenciadora para o mercado de trabalho, estudar assumia o sentido de uma obrigação: "Infelizmente, vou ter de colocar a cara no livro e no caderno e estudar!" (Cintia, 22 anos).

Assim, o olhar sobre suas histórias de escolarização era marcado por ambiguidades. Abandonos e tentativas de retomar os estudos eram constantes. Havia a constatação de que estudar era um grande sacrifício, exigindo um grande esforço para se motivar. Ao mesmo tempo, os jovens reconheciam a importância da certificação escolar, reduzida, em grande parte, às exigências do mercado de trabalho. Nesse terreno dúbio, havia uma propensão à autorresponsabilização, seja atribuindo a si uma incapacidade para estudar, seja assumindo a culpa por não conseguir adaptar-se à disciplina escolar.

\section{O trabalho: experiências da inclusão}

subalterna

0 trabalho é uma experiência comum para todos os entrevistados, revelando sua centralidade na experiência da juventude no Brasil (GUIMARÃES, 2005). Em geral, as primeiras experiências de trabalho deram-se ainda na infância. Alguns auxiliavam os pais nas atividades agrícolas, como no caso dos jovens que migraram. Para as mulheres, as ocupações como domésticas foram a porta de entrada para o mundo do trabalho. Outros iniciaram suas atividades em pequenos bicos durante a adolescência.

Dentre os entrevistados, duas jovens exerciam atividades autônomas, sendo uma faxineira e outra vendedora; três jovens tinham vínculo formal com o emprego; outro estudante era aposentado por invalidez em virtude de um atropelamento por ele sofrido. Os quatro jovens restantes estavam desempregados no momento da pesquisa.

Suas trajetórias ocupacionais revelam alguns aspectos comuns, como a entrada precoce no mundo do trabalho e o trânsito constante por ocupações precárias e em tempo parcial. Por outro lado, há diferentes expectativas 
e sentidos elaborados em relação ao trabalho, revelando também diferentes disposições em relação à situação atual e ao futuro profissional.

Dentre os jovens, Marcos parece ser aquele que mais valorizava sua atual ocupação. Com 26 anos, casado, sua inserção no trabalho iniciou-se aos 9 anos de idade com a prestação de pequenos serviços na casa da fazenda onde seu pai trabalhava, sendo posteriormente contratado como trabalhador agrícola. Aos 19 anos, já casado e insatisfeito com sua condição de vida, decidiu migrar para Belo Horizonte. Morando com um tio nesse período inicial, começou a trabalhar como servente de pedreiro e construiu a casa em um município vizinho à capital, onde residia com a esposa e a filha. Aos poucos, conseguiu ser promovido até chegar à função de encarregado de carpintaria em uma construtora. $\mathrm{Na}$ época das entrevistas, ele trabalhava em uma obra próxima do local onde funcionava sua turma do ProJovem. Segundo Marcos, a decisão de migrar para a capital estava ligada ao desejo de melhorar sua condição social por meio do trabalho.

Por intermédio da empresa em que trabalhava, Marcos fazia um curso de leitura e interpretação de projetos na área da construção civil. 0 curso era realizado aos sábados, no período da tarde, na sede do Sindicato das Empresas de Construção Civil. Além disso, ele costumava fazer horas-extras nos finais de semana. Assim, o trabalho assumia uma grande centralidade em sua vida, de modo que em torno dele organizavam-se suas experiências atuais e suas perspectivas futuras. Parecia haver, a partir de sua fala, uma confiança em suas perspectivas futuras como trabalhador da construção civil, o que pode ter influências da expansão imobiliária vivida no país no momento da entrevista.

Por outro lado, seu discurso deixava margens a mudanças de planos. Oriundo de uma região mineira conhecida pelo grande movimento migratório em direção aos Estados Unidos e a alguns países da Europa, com parentes residindo nessa condição, Marcos parecia ainda ter a migração como uma possibilidade futura:

Os cursos que tem lá [EUA], aqui são totalmente diferentes. E o trabalho lá também é mais valorizado do que aqui. Lá você trabalha muito, mas ganha bem. Aqui não. Aqui é o contrário, você trabalha muito e ganha pouco, entendeu? 0 serviço lá, a mão de obra lá é bem mais valorizada do que aqui. Eu penso num lugar desse assim... Ir trabalhar com a cabeça, juntar uma grana boa... Juntar uma grana boa, comprar uma fazenda e ficar quieto. Só tomar conta e ficar sossegado.

Se o trabalho como operário da construção civil assumia tal relevância na experiência social de Marcos, isso não nos autoriza a falar em uma identidade operária fixa e imutável, pensada na perspectiva de uma trajetória construída a partir de um posto de trabalho ocupado por toda a sua vida produtiva até a aposentadoria e que garantisse o exercício de seu papel de provedor da família. Seu discurso acenava para o imprevisível, para outras possibilidades que ele poderia aproveitar caso o cenário fosse favorável, para uma atividade que lhe permitisse "trabalhar com a cabeça" (em oposição ao trabalho manual), "juntar uma boa grana” e construir sua estabilidade financeira voltando às suas origens ("comprar uma fazenda e ficar quieto").

Não podemos dizer que ele tivesse uma perspectiva meramente instrumental do trabalho. 0 trabalho parecia ter um valor central em sua vida, mas a partir de uma forte valorização do aspecto de sua retribuição material ou como símbolo de status. Havia, assim, uma síntese produzida a partir do caráter provisório que as ocupações adquirem nas sociedades contemporâneas. Diante de tal imprevisibilidade, é preciso estar atento a outras oportunidades, e uma delas era migrar para outros mercados, como o trabalho clandestino no exterior. 
Outros jovens, a partir das experiências vividas em trabalhos mais precários, tendiam a canalizar suas expectativas em direção a um emprego qualquer. É o caso de Carla, que trabalhava desde a adolescência como faxineira, três vezes por semana, recebendo uma renda de 35 reais por dia. Sua socialização para o trabalho começou na família, nas atividades domésticas em casa ou ao acompanhar sua mãe no trabalho em outras residências. Por volta dos 15 anos de idade, Carla começou a fazer bicos e a prestar serviços de faxineira como autônoma, atividade que ela gostaria de deixar por um "trabalho fixo", de preferência no comércio. No entanto, ela não parecia ter muita confıança nas possibilidades de conseguir estabelecer-se em outra atividade. Diferentemente de Marcos, suas perspectivas eram bem mais modestas e acenavam na direção de "um emprego qualquer", que lhe permitisse "casar, ter uma família, filhos".

Guy Bajoit e Abraham Fransen (1997), ao pesquisarem os sentidos do trabalho entre jovens belgas, constataram, entre alguns, a tendência a alimentarem expectativas reduzidas em relação ao trabalho, valorizando aspectos instrumentais (ganho, ocupação do tempo, status social) em detrimento de sua dimensão expressiva. Tal postura, que os autores denominaram garantismo, manifestava-se principalmente entre

jovens cuja experiência da precariedade origina-se frequentemente numa socialização familiar que oferece recursos frágeis ou inadequados e é confirmada pelo veredito do sistema escolar. (p. 81)

Inserir-se em atividades no setor de comércio era uma perspectiva vislumbrada geralmente pelas mulheres. Dentre as jovens entrevistadas, duas vieram do interior do Estado para trabalhar em casas de família como domésticas ou babás. As longas jornadas e o isolamento social que caracterizam essas atividades, além da dificuldade em conseguir conciliar estudo e trabalho, levaram as duas a procurarem outra ocupação.
Cátia trabalhava como vendedora de calçados em um shopping popular durante a semana e fazia bicos em uma feira de artesanato aos domingos pela manhã. Sua trajetória em relação ao trabalho foi marcada pelo esforço para conciliar estudos e trabalhos. Algumas vezes, ela se inscreveu em cursos de EJA, os quais acabava abandonando em virtude das dificuldades para conciliar trabalho doméstico e aulas.

Débora era vendedora autônoma e cuidava de uma pessoa idosa três vezes por semana. No momento da pesquisa, residia com uma amiga. Ela também veio do interior do Estado para trabalhar em Belo Horizonte como babá. Segundo ela, suas dificuldades para prosseguir nos estudos estavam associadas às restrições impostas pelo trabalho doméstico. Muitas vezes, ela teve de interromper o curso pois a rotina de trabalho não permitia frequentar as aulas, porque ficou desempregada ou mesmo porque mudou de emprego, indo residir em uma região distante da escola. Em virtude de sua história de vida, seu discurso girava em torno da ideia de "recuperar o tempo" perdido em sua escolarização. Ela dava uma grande ênfase ao esforço individual: "Basta querer! Nunca é tarde para começar!”. O sentido de estudar no ProJovem estava associado às muitas oportunidades que ela perdeu por não ter certificação escolar. Assim, seu esforço para concluir a educação básica dizia respeito ao desejo em conseguir um trabalho em melhores condições que o atual.

Se, para alguns entrevistados, trabalhar era uma condição para continuar estudando, outros declararam que decidiram afastar-se do trabalho para cursar o ProJovem. Eram os casos de Diego, Cintia, Jonathan e Bruno. Apesar de não podermos afirmar que se tratasse exatamente de desemprego voluntário, tendo em vista que a perspectiva de conseguir uma ocupação estava sempre presente para eles, esses jovens não se sentiam tão pressionados quanto os outros, em especial, devido ao fato de esse afastamento do emprego ter se dado com o consentimento de suas famílias, que os auxiliavam em suas necessidades básicas. Além disso, 
esporadicamente eles faziam pequenos bicos como pedreiros, ajudantes em eventos etc.

Entre eles, Cintia e Jonathan eram os que tinham melhores condições de administrar uma situação de desocupação temporária. Ela morava com o namorado, a mãe, um irmão e o avô. A família mantinha-se com a pensão do avô e a renda do trabalho do irmão e do namorado. Cintia já havia passado por diversos tipos de ocupações, como babá, balconista de bar e de lanchonete, atendente de padaria e bicos em festas infantis.

Não podemos dizer que Cintia tenha optado por não trabalhar exclusivamente em função do ProJovem. Ao que parece, ela sempre foi poupada do trabalho por seus familiares, e as melhores condições de renda que a família vivia naquele momento possibilitavam que ela permanecesse na inatividade. Sua aspiração era uma ocupação que permitisse conciliar estudo e trabalho, embora ela não demonstrasse nenhuma identificação com os estudos. Ao contrário, estudar era associado por ela a um grande sacrifício: "Nossa, eu ia para a escola só para fazer bagunça mesmo, era só para zoar mesmo". Assim, o sentido de voltar a estudar, como em outros casos, era uma estratégia de certificação para aumentar as chances de concorrer a empregos melhores do que aqueles pelos quais ela já havia passado. Ao falar de suas ocupações anteriores, Cintia fazia muitas críticas às condições e às relações de trabalho experimentadas em sua trajetória. Ela expressava uma aspiração a uma melhor condição social:

Mas eu sei que um dia, ao invés de eu ser a empregada, a contratada, eu vou ser a patroa, né? Eu vou ser quem vai estar empregando, se eu estudar!

Para isso, ela planejava concluir o ensino médio, fazer um cursinho, fazer um concurso público e cursar faculdade "em veterinária ou medicina”. Mesmo que houvesse grande distância entre os planos concebidos e as condições reais de sua realização, a partir de uma melhor condição social vivida por sua família, era possivel a ela ter aspirações mais amplas do que as dos colegas.

Também Jonathan, de 19 anos, somente estudava. Antes, ele trabalhava temporariamente como servente de pedreiro ou fazia outros bicos quando era convidado por alguém. Morava com a mãe, a irmã e um irmão, e tinha o apoio deles para concluir os estudos. Ao falar de suas aspirações quanto ao trabalho, ele valorizava aspectos extrínsecos ao próprio trabalho, como deixar um tempo livre para si e proporcionar uma boa renda.

Dentre aqueles que não trabalhavam, Bruno, de 24 anos, tinha a pior condição socioeconômica. Ele morava sozinho em um barraco alugado. Era solteiro e tinha uma filha de um relacionamento anterior. Sua trajetória no trabalho iniciou-se aos 17 anos como ajudante em um ferro-velho, ganhando trinta reais por semana. Trabalhou ainda como entregador de supermercados, gari e carregador em uma distribuidora de refrigerantes. Na época da pesquisa, participava de um projeto social em que aprendia design gráfico. Ele pretendia trabalhar com algo associado à sua prática com o grafite. Ao falar do trabalho, Bruno contrapunha as experiências anteriores à possibilidade de trabalhar com arte: "Se você é bom de desenho, vai ficar carregando peso para quê?”.

Apesar de sua condição social ser pior em relação à dos outros jovens, o que poderia levá-lo a valorizar aspectos relativos à estabilidade e ao retorno financeiro, o desejo de Bruno era dedicar-se a uma atividade com a qual ele se identificasse. Talvez o contato com amigos do movimento hip-hop e sua experiência no projeto social alimentasse tais expectativas tão singulares em relação às dos outros entrevistados. Parece haver em sua história um peso grande das relações de sociabilidade tecidas a partir do projeto social, do grafite e do hip-hop. Para ele, não se colocava a questão de fazer grandes planos ou a ideia de se sacrificar em uma atividade qualquer para garantir alguma segurança financeira futura. De todos os jovens, Bruno era aquele que mais expressava uma perspectiva colada ao presente. Diante da 
incerteza, ele preferia não fazer planos, experimentando o presente e buscando alternativas para responder às demandas imediatas.

Apesar da proximidade de suas experiências, os sujeitos da pesquisa elaboravam diferentes sentidos e expectativas em relação ao trabalho. Pode-se perceber, assim como em outros estudos (CORROCHANO, 2004), diferenças nessa direção dependendo do sexo, da fase da vida, da origem rural ou urbana, do estado civil etc. Para aqueles que vivenciavam condições mais precárias, havia a expectativa de conseguir um trabalho fixo qualquer, como no caso de Carla.

Outros, como Ricardo e Leonardo, pareciam conformados com a atual ocupação. Ricardo, casado e com três filhas, trabalhava como garibador ${ }^{3}$ de automóveis em uma revendedora. Embora pouco qualificado, seu trabalho proporcionava-lhe uma situação relativamente estável e ele parecia conformado com isso. No caso de Leonardo, havia o fato de ter se aposentado como porteiro depois de um acidente de trânsito que o deixou com um dos braços incapacitado. Ele tinha, portanto, uma renda garantida que lhe permitia viver na inatividade.

Para aqueles que migraram em busca de trabalho, havia, de uma maneira mais forte, a expectativa de que o trabalho possibilitasse uma melhor condição social. Para outros, o sentido do trabalho dirigia-se a ter um bom emprego, em boas condições e relações de trabalho, que não exigisse muito esforço. Diferentes sentidos e expectativas em relação ao trabalho parecem constituir-se a partir de um solo comum vivido por esses jovens, caracterizado pela precariedade e pelas incertezas que marcam as experiências no mundo do trabalho nas sociedades contemporâneas. De acordo com Nadya Guimarães (2005), tal centralidade "não advém dominantemente de seu sentido ético", mas de sua "urgência como problema" (p. 159). Apesar de não perder sua dimensão como valor que estrutura a vida desses jovens, para a grande maioria, é como fator de risco (precariedade, ausência) que

3 - Pessoa que trabalha com limpeza, polimento e tratamento dos componentes internos (bancos, painel, portas etc.) dos carros. ele se manifesta. Assim, o programa será, para muitos, a oportunidade de fazer frente à necessidade de inserir-se no mercado de trabalho, garantir o emprego atual e até melhorar em relação à atual ocupação.

\section{Ser jovem: cotidiano e projetos de futuro}

Em geral, o cotidiano dos jovens entrevistados organizava-se em torno do trabalho, do curso e da casa. Havia alguns poucos relatos de outros espaços frequentados, como as igrejas evangélicas e um projeto social, mencionado por um dos jovens. Na maioria dos casos, porém, a rotina de trabalho, a família e o cansaço gerado, além do fato de residirem distante do trabalho e do curso, restringiam muito as possibilidades de eles frequentarem outros espaços e círculos sociais.

Parecia haver também a tendência a um refluxo da sociabilidade com o passar dos anos, quando a casa e a família ganhavam maior relevância em relação aos grupos de amigos, por exemplo. Em alguns casos, a saída da adolescência era marcada por um movimento de voltar-se mais para o espaço familiar e reduzir as atividades de lazer e sociabilidade com grupos maiores de amigos. Cintia, de 22 anos, por exemplo, relatou que durante toda sua adolescência divertia-se muito, saindo para festas e bares com os amigos. Muitas vezes, isso ocorria durante toda a semana, o que já não era comum na época da entrevista: "Hoje em dia não! Hoje em dia eu saio para uma coisa mais leve, aquela coisa mais suave". Seus momentos de lazer eram geralmente com o namorado, a família ou alguns poucos amigos.

Caso semelhante é o de Jonathan, de 19 anos. 0 que mais marcou sua adolescência foram as festas e passeios com os amigos. Ele sempre foi muito popular na escola e no bairro e até o momento da entrevista ainda tinha o hábito de sair com os colegas nos finais de semana para se divertir. Mas parecia haver um movimento de arrefecimento dessas atividades: 
A última coisa no mundo que eu queria quando eu era adolescente é ficar dentro de casa! E uma coisa que eu acho que hoje é sagrado é ficar dentro de casa!

Para alguns, essas questões estavam ligadas ao lugar de provedores que passaram assumir. Para outros, era a experiência de uma nova fase da juventude. Parece haver aqui uma relação com a busca pelo curso, uma vez que o desejo por retomar os estudos já não competia com a sociabilidade juvenil. Podemos dizer que, nesse novo momento da vida de tais jovens, a escola assumia um novo lugar em seus planos.

Em relação a esse aspecto, Bruno destoava do conjunto. Como foi relatado, além do ProJovem, ele participava de um projeto social voltado para a formação de jovens na área de mídias. Por meio desse projeto, Bruno inseriu-se em algumas redes sociais na internet ( $f a$ cebook, msn). Além disso, articulava-se com outros jovens do movimento hip-hop em Belo Horizonte, participando de algumas de suas atividades. Diferentemente dos demais jovens, Bruno parecia mais aberto a outros espaços de sociabilidade juvenil proporcionados por alguns grupos culturais da cidade.

Dentre os entrevistados, ele era aquele que mais encarava sua fase da vida como um momento de experimentação. Apesar de já estar com 24 anos, residir por conta própria, ter uma filha e já ter uma relativa trajetória no mundo do trabalho, Bruno não se assumia como um jovem-adulto. Para ele, a juventude caracterizava-se pelas oportunidades de experimentação que possibilitava, de apostar em fazer algo de que gostasse. "Marcar presença" e "ter atitude" eram referências em sua fala, demarcando a postura de uma valorização do tempo presente, talvez como uma forma de lidar com as incertezas que ele vivia em seu cotidiano.

Segundo Carmem Leccardi (2005), as trajetórias biográficas na contemporaneidade estão fortemente marcadas por novas relações com o tempo. Os indivíduos já não se orientam em relação a um futuro projetado, mas em relação às experimentações possíveis no presente. Como nômades, as pessoas transitam entre diversos campos possíveis, em função da satisfação mesma de experimentar e

não segundo a costumeira referência a um itinerário marcado por experimentos e erros, com o objetivo de identificar as vias mais idôneas para atingir um dado objetivo. (p. 47)

A autora fala de outro contexto social as sociedades europeias - em que as experiências individuais podem fazer prevalecer uma relação mais tênue com o tempo. No entanto, guardadas as devidas proporções, parece ser possível alguma aproximação com esse tipo de experiência entre os jovens brasileiros, mesmo entre aqueles em cujas vidas as pressões pelas demandas por necessidades básicas pesam mais fortemente.

Nos relatos, pode-se perceber, então, uma diversidade das experiências juvenis. Apesar da proximidade em termos da origem sociocultural e de alguns traços presentes em suas trajetórias, há singularidades que produzem diferentes modos de viver essa fase da vida. Em geral, todos se consideravam jovens e associavam à juventude características como alegria, força e disposição. Mas havia uma tendência a dividir-se entre alguns que estavam mais abertos às experimentações dessa fase da vida e outros que ressaltavam os compromissos e a maturidade, "apesar da juventude".

Os mais velhos, ou aqueles que dependiam mais do trabalho para manter a si mesmo e à sua família, identificavam-se como jovens-adultos. Cátia tinha 24 anos e dizia ser o "esteio da família" desde muito nova. Apesar de seus pais e irmãos morarem no interior, muitas decisões não eram tomadas sem uma consulta a ela. Ela dizia ter amadurecido precocemente, pois com 16 anos já trabalhava em Belo Horizonte como acompanhante de uma idosa, o que fazia com que ela se identificasse pouco com os adolescentes. 
Ao falar de seus planos futuros, Cátia demonstrou muita hesitação entre aquilo que desejava e suas possibilidades de realização. Seu sonho era fazer faculdade de enfermagem, mas tinha dúvidas se conseguiria realizar seu desejo, pelo longo tempo e esforço que isso demandaria. Uma possível estratégia vislumbrada por ela como forma de inserção nessa área era fazer um curso técnico, exercendo a atividade antes de iniciar o curso superior. Mas, para ela, essas seriam possibilidades futuras ainda muito incertas. $\mathrm{Na}$ condição em que vivia, residindo sozinha e mantendo-se por conta própria, sustentada por um trabalho instável, suas preocupações voltavam-se mais para as demandas imediatas e não possibilitavam a ela fazer grandes planos.

Quando perguntados sobre seus projetos para o futuro, todos os entrevistados faziam planos de dar continuidade aos estudos. A conclusão do ensino fundamental trazia para eles a perspectiva de fazer o ensino médio. No entanto, os planos quanto a continuar estudando assumiam diferentes pesos e conotações para cada caso. Ricardo, por exemplo, vinculava seus projetos ao futuro dos filhos. Depois de passar parte da vida na prisão e reinserir-se em um emprego formal, mesmo que com baixa qualificação, ele parecia resistir a elaborar grandes planos. Havia em seu depoimento uma tendência a acentuar os limites que a vida lhe impunha. Para ele, seus planos referiam-se a dar boas condições de vida e ser um exemplo para os filhos. Estudar era um desdobramento natural da conclusão do programa, mas era algo para o qual ele mantinha certa distância, uma margem de segurança, como se quisesse precaver-se de futuras decepções: "Mas se eu continuar estudando, a primeira bomba que eu tomar eu paro!”.

Assim, ao mesmo tempo em que afirmava planejar continuar os estudos, Ricardo parecia querer justificar uma possível desistência. Para ele, era algo que desejaria fazer, mas dentro de suas possibilidades, sem o longo tempo e a pressão que o ensino médio impõe. Continuar os estudos era uma possibilidade por ele considerada com certo distanciamento.
Havia também uma resistência a fazer planos para um futuro distante, que para ele não era possível imaginar, nem administrar. Eram as exigências mais imediatas da vida que o preocupavam (os filhos, o trabalho).

0 que parece conformismo diante de sua atual condição pode ser visto como um princípio de realidade. José Machado Pais (2001), ao pesquisar trajetórias de trabalho entre jovens portugueses, lembra-nos de que as escolhas (O que fazer? O que quero fazer?) tendem a articular dois princípios da realidade: um teto cultural definido por normas, valores e crenças institucionais ( $O$ que se deve fazer?), e um solo material delimitado por condições de vida e estruturas sociais ( $O$ que se pode fazer?). Assim, embora houvesse o desejo e o sentimento de uma imposição social para continuar os estudos, pode ser que a consciência dos limites e das dificuldades alimentassem um distanciamento dele em relação a grandes planos nesse âmbito.

Carla, por sua vez, parecia mais segura quanto ao desejo de continuar os estudos no ensino médio, sem desconsiderar as dificuldades quanto ao grau de exigência desse nível de ensino e a dificuldade para encontrar uma escola pública que pudesse frequentar. Ao mesmo tempo, ela fazia outros planos: conseguir um emprego fixo, um "serviço digno", casar-se e ter filhos. Para ela, isso significava "garantir o básico" para depois sonhar com outras perspectivas. Assim como Ricardo, ela parecia manter uma reserva quanto aos seus sonhos que pareciam inalcançáveis. Para isso, agarrava-se ao desejo de ter um bom emprego qualquer, "longe da faxina", como se quisesse garantir suas condições para poder fazer planos.

A maioria dos entrevistados planejava continuar os estudos em algum supletivo ou programa de EJA, de maneira que pudessem aligeirar o processo de passagem pelo ensino médio e fazer algum curso superior ou profissionalizante posteriormente. A prática de buscar formas de aligeirar o processo, quase sempre associada à ideia de "recuperar o tempo perdido”, parece também ser um traço muito 
forte entre jovens das camadas populares que vivenciaram percursos escolares precários e atribulados (ZAGO, 2000).

Para alguns, havia o sonho de fazer faculdade, muitas vezes em cursos de alto prestígio social. Talvez a experiência recente do PROUNI Programa Universidade Para Todos, do Governo Federal -, que favoreceu a expansão das matrículas na educação superior de alunos provenientes das camadas populares, tenha contribuído para que alimentassem tal expectativa. Parece ser esse o caso de Cintia. Ela afirmou ter um irmão que estava cursando economia, embora não tenha esclarecido em quais condições. Em certo momento, ela parecia fazer uma relação com as políticas de financiamento do ensino superior para jovens pobres e as condições de realização de seu projeto de fazer veterinária ou medicina.

A experiência do grupo social também parecia influenciar muito nas decisões de alguns desses jovens. No caso de Jonathan, a trajetória dos amigos e parentes acenava para que ele cursasse o ensino superior na área de informática, área em que a irmã e um amigo já atuavam. Sua escolha dava-se a partir de critérios práticos, pois, segundo ele, tratava-se de uma atividade fácil que ele poderia executar com o apoio de pessoas próximas, com bom retorno financeiro e menor desgaste físico.

Para Marcos, o projeto de fazer um curso superior em engenharia nascia de sua experiência como encarregado na construção civil. Ele também fazia referência à experiência de um colega que conseguiu fazer o curso em uma faculdade privada. Segundo ele, seu amigo teve muitas dificuldades para pagar o curso, mas aos poucos foi parcelando suas dívidas com a faculdade e assim conseguiu concluí-lo. Seus planos eram fazer um curso supletivo ou frequentar a EJA para concluir o ensino médio e posteriormente cursar uma faculdade. Apesar da clareza com que falava de seus projetos futuros, ele deixava escapar nas entrelinhas uma insegurança com relação às possibilidades de sua realização:
Eu sei que não vai ser fácil para mim, mas eu quero fazer minha faculdade de engenharia. Se eu não aguentar, eu desisto. Mas eu vou começar, se Deus quiser!

Como compreender essa diversidade de perspectivas e a complexidade das escolhas? Elas exigem um olhar para o contexto - social, histórico, individual - a partir do qual os sujeitos fazem suas escolhas, constroem estratégias e elaboram práticas para a realização de suas expectativas. Norbert Elias (1995) adverte-nos de que "os anseios não estão definidos antes de todas as experiências”, mas vão sendo definidos "ao longo do curso da vida" (p. 13), dependendo do convívio com outras pessoas, dos acontecimentos mais ou menos graves, das respostas dadas pelo meio social ao desejo das pessoas etc. Na mesma direção, Gilberto Velho (2003) lembra-nos de que:

Os projetos individuais sempre interagem com outros dentro de um campo de possibilidades. Não operam num vácuo, mas sim a partir de premissas e paradigmas culturais compartilhados por universos específicos. Por isso mesmo são complexos e os indivíduos, em princípio, podem ser portadores de projetos diferentes, até contraditórios. (p. 46)

Em alguns casos, os depoimentos pareciam indicar pragmatismo ou uma relação instrumental com as escolhas. Mas o que pode parecer, aos nossos olhos, uma tendência a pular etapas ou uma forma de burlar o que seria o percurso natural de escolarização e profissionalização, para esses jovens, são estratégias para administrar as incertezas e as condições limitadas que a vida lhes impôs, uma forma de ampliar seus horizontes encurtados pelas trajetórias de vida construídas em contextos de desigualdade.

Muitas vezes, essas estratégias resumiam-se nas expressões correr atrás e ser alguém. Elas traduziam uma constatação da posição menos favorecida (atrás) em que se 
encontravam em relação à escolarização e ao trabalho de outros jovens ou da ausência de reconhecimento social, uma vez que ser alguém consiste em superar a condição de ser ninguém. Ao mesmo tempo, traziam o sentido de que eles deveriam empenhar-se e de que isso dependia unicamente deles, revelando uma postura de autorresponsabilização individual pelo futuro. Segundo nos lembra Danilo Martuccelli (2007), nas sociedades contemporâneas, os indivíduos são colocados no centro da vida social: a vida de cada um é fruto de sua obra. Os indivíduos assumem a tarefa de se produzirem como sujeitos e passam a assumir também uma responsabilidade maior por seus destinos.

\section{Considerações finais}

Os dados sobre as trajetórias desses jovens aproximam-se de alguns estudos sobre o perfil dos estudantes do ProJovem Urbano em outros contextos (ANDRADE; ESTEVES; OLIVEIRA, 2009; SILVEIRA, 2009). Em sua grande maioria, são jovens das camadas populares, negros, em condições precárias de trabalho ou desempregados, e com uma sociabilidade restrita em relação a outros estratos da população. São jovens marcados por percursos escolares acidentados e com trajetórias escolares familiares de insucesso, com pais geralmente exercendo atividades manuais. Isso indica o peso das posições sociais na configuração das trajetórias juvenis que, se não determinam os destinos pessoais, apresentam-se como condicionantes importantes nos percursos de cada um. Ou seja, as desigualdades sociais têm um papel central nas trajetórias de vida de uma grande parcela da juventude latino-americana, com impactos sobre suas experiências atuais e suas expectativas em relação ao futuro. Do ponto de vista da escolarização, as desigualdades em relação ao capital cultural herdado produzem diferentes expectativas e projetos futuros (DÁVILA; GHIARDO; MEDRANO, 2005).

Com base nesse solo comum, foi possível perceber uma diversidade de experiências a partir das quais são produzidos diferentes significados e motivações em relação à escolarização, o que delimitava também a relação construída com o programa. De uma maneira geral, a busca pela certificação escolar era o principal interesse dos participantes. Para a grande maioria deles, o diploma era valorizado em função das expectativas quanto a conseguir uma melhor posição no mercado de trabalho. Ao mesmo tempo, alguns acentuavam aspectos ligados ao reconhecimento social e familiar ou ao fato de que o curso era uma oportunidade para encontrar colegas e sair do espaço doméstico, aspecto verificado com maior ênfase entre as mulheres.

Um elemento não abordado neste texto refere-se à predominância de mulheres entre os alunos, aspecto verificado em outro estudo sobre o perfil dos estudantes do programa em âmbito nacional (ANDRADE; ESTEVES; OLIVEIRA, 2009). Algumas hipóteses poderiam explicar esse fenômeno: uma maior dificuldade das jovens para concluírem o ensino fundamental, em virtude de gravidez e/ou casamento, uma maior disposição e persistência das mulheres para os estudos etc.

Essas questões, que merecem um aprofundamento analítico, são fundamentais para compreender as dinâmicas e interações tecidas pelos jovens no cotidiano do programa. Cabe perguntar quais respostas as políticas públicas têm dado a dilemas e demandas juvenis tão heterogêneos. Eles têm sido incorporados na agenda pública como sujeitos de direitos? 0 ProJovem Urbano constitui-se como uma ação capaz de incorporar a diversidade de experiências, necessidades e aspirações de seu público, fazendo frente à condição social desigual a que estão submetidos? 


\section{Referências}

ANDRADE, Eliane Ribeiro; ESTEVES, Diego Carlos Gil; OLIVEIRA, Edna Castro de. Composição social e percursos escolares dos sujeitos do ProJovem: novos/velhos desafios para o campo da Educação de Jovens e Adultos. Em Aberto, Brasília, v. 22, n. 82, p. 73-89, nov. 2009.

BAJOIT, Guy; FRANSEN, Abraham. 0 trabalho, busca de sentido. Revista Brasileira de Educação, São Paulo, n. 5/6, p. 76-96, maio-dez. 1997.

BELO HORIZONTE. Prefeitura Municipal. Secretaria Municipal de Educação. Coordenação Municipal do Projovem Urbano de Belo Horizonte. Relatório de Avaliação: Programa Nacional de Inclusão de Jovens. ProJovem Urbano Belo Horizonte. Entrada 2009. Belo Horizonte, maio 2011.

BRASIL. Secretaria Geral da Presidência da República. Secretaria Nacional da Juventude. PROJOVEM. Programa Nacional de Inclusão de Jovens: Educação, Qualificação e Ação Comunitária. Brasília: Secretaria Nacional de Juventude, 2005.

CHARLOT, Bernard. Da relação com o saber: elementos para uma teoria. Porto Alegre: Artmed, 2000.

CORROCHANO, Maria Carla. Jovens olhares sobre o trabalho: um estudo dos jovens operários e operárias de São Bernardo do Campo. Dissertação (Mestrado) - Faculdade de Educação, Universidade de São Paulo, São Paulo, 2004.

DÁVILA, Oscar; GHIARDO, Felipe; MEDRANO, Carlos. Los desheredados: trajetórias de vida e novas condições juvenis. Santiago de Chile: CIDPA Ediciones, 2005.

DUBET, François. A escola e a exclusão. Cadernos de Pesquisa, n. 119, p. 29-45, jul. 2003.

ELIAS, Norbert. Mozart: sociologia de um gênio. Rio de Janeiro: Jorge Zahar Editora, 1995.

GUIMARÃES, Nadya Araujo. Trabalho: uma categoria-chave no imaginário juvenil? In: ABRAMO, Helena W.; BRANCO, Pedro Paulo M. Retratos da juventude brasileira. São Paulo: Instituto Cidadania; Editora Fundação Perseu Abramo, 2005. p. 149-174.

LECCARDI, Carmem. Por um novo significado do futuro: mudança social, jovens e tempo. Tempo Social, Revista de Sociologia da USP, São Paulo, v. 17, n. 2, p. 35-58, nov. 2005.

MARTINS, José de Souza. A exclusão social e a nova desigualdade. São Paulo: Paulus, 1997.

MARTUCCELLI, Danilo. Cambio de rumbo: la sociedad a escala Del individuo. Santiago: LOM Ediciones, 2007.

NERI, Marcelo. Motivos da evasão escolar. S/I: Movimento Todos pela Educação; Fundação Educar Dpaschoal; Instituto Unibanco; Fundação Getúlio Vargas, s/d.

PAIS, José Machado. Ganchos, tachos e biscates: jovens, trabalho e futuro. Porto: Ambar, 2001.

SILVEIRA, Olívia Maria Costa. 0 unicórnio e o rinoceronte: análise do ProJovem a partir da percepção de seus beneficiários. Dissertação (Mestrado) - Faculdade de Educação, Universidade Federal da Bahia, Salvador, 2009.

VAN ZANTEN, Agnès. A influência das normas de estabelecimento na socialização profissional dos professores: 0 caso dos professores dos colégios periféricos franceses. In: TARDIF, Maurice; LESSARD, Claude. Ofício de professor: história, perspectivas e desafios internacionais. Petrópolis: Vozes, 2008. p. 200-216.

VELHO, Gilberto. Projeto e metamorfose: antropologia das sociedades complexas. Rio de Janeiro: Jorge Zahar Editor, 2003. 
ZAGO, Nadir. Processos de escolarização em famílias de camadas populares - As contradições da obrigatoriedade escolar. In: . Família e escola: trajetórias de escolarização em camadas médias e populares. Petrópolis: Vozes, 2000.

Recebido em: 28.11.11

Aprovado em: 11.04.12

Geraldo Leão é doutor em Educação pela Universidade de São Paulo, professor adjunto da Faculdade de Educação, do Programa de Pós-Graduação em Educação da Universidade Federal de Minas Gerais (UFMG), e membro do Observatório da Juventude da UFMG.

Symaira Poliana Nonato é licenciada em Pedagogia pela Universidade Federal de Minas Gerais (UFMG), mestranda em Educação do Programa de Pós-Graduação em Educação da UFMG, pesquisadora do Observatório da Juventude da UFMG e integrante do GIZ (Rede de Desenvolvimento de Práticas do Ensino Superior - UFMG). E-mail: sypoli@yahoo.com.br. 